\title{
THE APPLICATION OF COLLOIDAL SURFACES AS A CATALYST OF CEMENT HYDRATION REACTIONS
}

\section{Alexandra Shyshkina ${ }^{1}$}

DOI: https://doi.org/10.30525/978-9934-26-021-6-43

Abstract. The purpose of this work is to establish the fundamental possibility of using complex complexes consisting of colloidal and molecular surfactants to catalyze the hydration of cement compositions, the study of mechanical properties. As a result of research, it was found that the introduction of colloidal surfactant into the reaction powder concrete leads to a sharp increase in the strength of concrete at the age of 7 days. It is noted the presence of the optimal content of colloidal surfactant in the amount of $0.0007 \%$ by weight of water, which ensures the formation of the maximum strength of the system. In the next step of the experiment, an additional molecular surfactant was introduced into the system. As a result of experiments it was found that the introduction of this substance increases the strength of concrete. Thus, it was found that dimers of colloidal surfactant, which are nanocatalysts for cement hydration reactions, lead to an increase in the strength of concrete and the rate of its formation.

\section{Introduction}

Every year in the world practice of concrete and reinforced concrete production the production of high-quality, high and especially strong concretes is growing rapidly and this progress has become an objective reality due to significant savings of material and energy resources.

Practically all countries actively develop new generations of concretes including with the accelerated terms of hardening and a set of durability especially in monolithic construction.

To accelerate the hardening of concrete in the manufacture of structures using a variety of methods:

- mechanical - increasing the specific surface of cement;

\footnotetext{
${ }^{1}$ Candidate of Technical Sciences, Associate Professor,
} Kryvyi Rih National University, Ukraine 
- thermal - the effect of elevated hardening temperature of concrete, both at normal atmospheric and at elevated pressure;

- chemical - the introduction of additives that accelerate hardening [1].

Each of these methods has its drawbacks.

Increasing the specific surface of cement has its limitations both in magnitude excess which leads to reverse aggregation of cement particles [2], and with the cost for manufacturing concrete , which significantly increase Xia.

Heat treatment of concrete also has its limitations. So even according to regulatory documents, to obtain high-quality (including frost-resistant) concrete, it is necessary to reduce the temperature of isothermal heating to $333 \mathrm{~K}$.

Traditionally, hardening accelerators are used to solve the problem of accelerating the formation of concrete strength [3]. However, their disadvantage is the interference in the chemical processes of hardening of binders, in particular, changes in their direction and the formation of new «non-standard» minerals [3].

Recently, a new approach in the production of composites due to the targeted regulation of the structure of materials at the nanoscale has become widely used. Nanomodification of the structure of composites due to the introduction of very small (up to $100 \mathrm{~nm}$ ) particles in relatively small quantities (up to $0.1 \%$ ) allows to obtain new in composition and qualitatively different in structure and properties structural and special materials due to increased activity of nanomaterials in the matrix structure. Researchers have shown the positive effect of artificially synthesized carbon nanotubes on improving the structure of cement stone, increasing its crack resistance and dynamic viscosity, water resistance, corrosion resistance. This effect is manifested because the carbon nanotubes in the matrix act as «embryos» of crystals of elongated shape, regulate the pore structure, contribute to its ordering in the direction of increasing conditionally closed micropores. These positive changes in the microstructure of cement stone, of course, affect the synthesis of artificial stone with the predicted high properties, which is extremely important for the creation of waterproof and corrosionresistant mortars and concretes.

Analysis of the results of research in the field of surfactants showed that almost all modern surfactants, which are used in concrete technology, refer to the molecular. At the same time, from the point of view of 
physicochemical mechanics the most expedient application of colloidal surfactants. These types of surfactants have features that distinguish them from other surfactants. So with increasing concentrations of the molecules of the surfactant's compounds form complexes, whose properties differ from the properties of molecules. First of all, complexes of two molecules are formed - dimmers, a further increase in concentration leads to the formation of complexes - micelles, which contain a significant number of molecules (Figure 1). Dimmers and micelles have the size and shape of nanoparticles. These nanoparticles - dimmers and micelles, to a much lesser extent compared to molecular surfactants shield the cement grains, which reduces their effect on the time of hardening and hardening of concrete.

In addition, dimmers and micelles of colloidal surfactants practically do not lead to hydrophobization of the surface of cement particles, absorbing hydrophobic particles that could get into the concrete mixture or are specially introduced into it.

Cement-water systems are complex systems that are part of a network of subreactions that relate to multicomponent reactions. One of the disadvantages of many multicomponent reactions, as well as «cementwater» systems is their rather low speed. Thus, for the reaction of hydration of cement minerals, the usual conversion time is several weeks or even months, so the search for effective methods to accelerate these reactions is an urgent task.

At this time, a stable trend has been the application of different types of catalysis to almost all reactions used in chemistry [4]. Even those

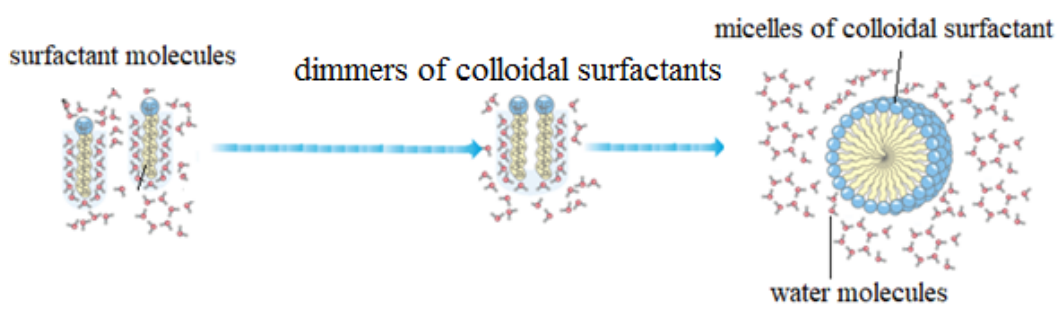

concentration of colloidal surfactant

Figure 1. Scheme of aggregation of molecules of colloidal surfactants 


\section{Alexandra Shyshkina}

transformations that were previously carried out without the use of any catalysts are now involved in the range of catalytic processes, reflecting the general direction.

It should be noted that the use of catalytic methods to increase the efficiency of multicomponent reactions has a special specificity. Therefore, traditional methods of accelerating chemical processes (the use of high temperatures, chemicals) often do not give the desired result. Of course, they act non-selectively, accelerating the two-component side effects, leading to the appearance of unwanted products in the system.

Thus, the use of the phase boundary in emulsions and suspensions to accelerate chemical reactions, as well as the conduct of syntheses in thin films on the surface of inorganic materials has allowed the development of new approaches to obtaining a variety of substances, including heterocyclic compounds. Such methods that increase the efficiency of chemical synthesis include the use of micellar solutions [5-7], which is becoming increasingly popular in recent years.

Interest in micellar solutions arises because of their general ability to solubilize chemicals in aqueous systems, and to act as a catalyst in chemical reactions. Micelle catalysis involves at least three stages [7]. First, the substrates bind to the micelle, and then in this micelle or on its surface there is a chemical reaction. In the third stage, the target product is isolated. The micellar accelerating effect is caused by a combination of non-covalent interactions between micelles on the one hand and reagents and the activated complex on the other hand. $\mathrm{T}$ ak a micellar solution can be regarded as microheterogeneous system, the reaction catalyzed micelles effect also affects local environment.

The orientation and concentration of molecules of solubilized substances in micelles leads to a significant change in the kinetics of chemical interaction of solubilized molecules with each other and with other substances dissolved in the medium. Most often, solubilization is accompanied by a significant increase in the rate of chemical interaction, which is the basis of a new direction of chemical kinetics - micellar catalysis [7]. This applies not only to micelles, but also to dimers of colloidal surfactants, which are micelles formed by the smallest number of molecules.

As a result of research synthesis of organic compounds established that mikroemulsiyni systems including surfactants, which form the count 
micelles and, alcohols $\left(\mathrm{C}_{5}-\mathrm{C}_{12}\right)$ and water acquired special significance in recent years [7].

At the same time, it is known [8; 9] that the introduction of polyalcohols into the composition of fine-grained concrete leads to an increase in their strength.

That is, the combination of colloidal surfactants and polyalcohols in a complex additive to the system «cement - water» leads both to an increase in the rate of hydration of cement, which will increase the rate of formation of concrete strength, and to increase the absolute value of this strength.

However, the use of micellar catalysis for multicomponent reactions has its limitations. For the appearance of a pronounced effect of acceleration, all the starting reagents must be well soluble in the polar part of the micelle, and if not, they will be in different phases and the reaction rate will drop sharply. Many micelle-forming surfactants also have specific catalytic activity. These limitations do not apply to the catalysis of multicomponent reactions by dimmers, as the wines have a structure different from the structure of the micelles.

Thus, based on the analysis of literature data, the existence of the phenomenon of catalysis of multicomponent hydration reactions of cement by combined micelles consisting of colloidal surfactants and polyalcohol [9; 10], data on the use of micellar catalysis of hydration reactions of cement using a mixture of colloidal and molecular surface -active substance in the scientific literature is not defined.

The aim of this study is to establish the possibility of using complexes consisting of colloidal and molecular surfactant, for catalytic hydration of cementitious compositions, the study of mechanical properties.

\section{Survey methodology}

For the production of concrete was used Portland cement M400 of PJSC "Kryvyi Rih Cement" (Ukraine) was used for concrete production. As components of Nanomodifiers used colloid of surfactants in a matter of sodium oleate (Simagchem Corp) and molecular surfactant Master Silk.

The components of the concrete mixture were dosed in the required quantities, according to the experimental plan, mixed in a laboratory mixer for 3 minutes. The resulting mixture was contained in a metal mold having a side size of $4 \times 4 \times 16 \mathrm{~cm}$. Formed in this way concrete samples hardened for 28 days at ambient humidity of $70 \pm 10 \%$ and an ambient temperature of $293 \pm 2 \mathrm{~K}$. 
Indirect evaluation of the effect of nano-modifiers on the hardening kinetics of cement at a water-cement ratio (W/C) of 0.26 was performed based on the results of determining the hardening time by standard methods.

The main indicator that characterized the hardening kinetics of cement after its hardening was the compressive strength of fine-grained concrete. The composition of concrete was held constant in all studies, with the ratio of the mass of cement in the mass of finely the filler and 0.5 . Determination of the compressive strength of the samples was performed in accordance with standard methods. The strength control of the samples was performed on a universal machine UMM-100.

\section{Findings}

The results of determining the time of hardening of the cement paste $(\mathrm{W} / \mathrm{C}=0.26)$ depending on the amount and type of surfactants are given in table 1.

Table 1

Influence of surfactants on the spread index and terms of hardening of cement dough

\begin{tabular}{|c|c|c|c|c|}
\hline \multirow{2}{*}{ № experiment } & \multicolumn{2}{|c|}{$\begin{array}{c}\text { Type and amount of } \\
\text { surfactants, } \mathbf{1 0}^{\mathbf{5}} \%\end{array}$} & \multicolumn{2}{c|}{$\begin{array}{c}\text { Terms of hardening, } \\
\text { h. }- \text { min. }\end{array}$} \\
\cline { 2 - 5 } & sodium oleate & Master Silk & Beginning & end \\
\hline 1 & - & - & $0-45$ & $2-16$ \\
\hline 2 & 4 & - & $0-48$ & $2-20$ \\
\hline 3 & - & 1 & $0-40$ & $1-56$ \\
\hline 4 & 4 & 1 & $0-45$ & $2-10$ \\
\hline
\end{tabular}

As the results of the experiments showed, neither the colloidal surfactant nor the molecular surfactant, which are used in such quantities, do not change the terms of hardening of the cement.

In inherit approx research found that the introduction of the fine-grained concrete colloidal surfactant leads to a sharp increase strength concrete (Figure 2) at the age of 7 days. The presence of the optimal content of colloidal surfactant in the amount of $0,0007 \%$ by weight of water, which ensures the formation of the maximum strength of the system. 
The rate of increase in the strength of concrete over time, as an indicator of the degree of hydration reactions of cement minerals, with a small content of colloidal surfactant, indicates their catalytic nature.

Given the general provisions of micellar catalysis, in the next stage of the experiment, an additional molecular surfactant (Master Silk) was introduced into the system. As a result of experiments, it was found that the introduction of this substance increases the strength of concrete at the age of 7 days (Figure 2).

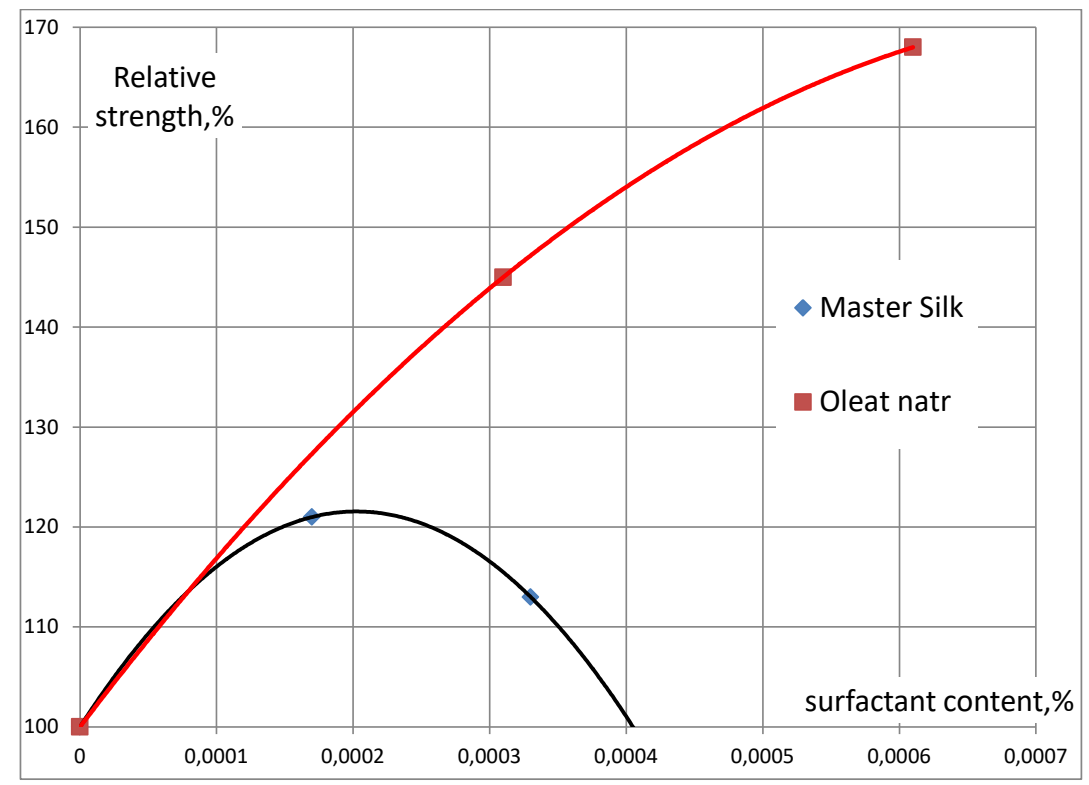

Figure 2. Relative strength of concrete (7 days)

At the age of 28 days, the nature of the effect of colloidal surfactant on the strength of the studied concrete is slightly different from that established at the age of 7 days (Figure 3).

The obtained data on the influence of a complex surfactant on the cement hardening process allow us to state the following: in the first stages of hardening the complex surfactant has practically no effect on the reaction rate. 
The results of determining the mechanical strength of cement stone samples in the early stages of hardening with $\mathrm{W} / \mathrm{C}=0.26$ indicate that the concentration of colloidal surfactant was significantly below the limit of micelle formation and below the concentration of micelle-dimmers nuclei.

Increasing the concentration of colloidal surfactant to the concentration when dimmers are formed, leads to an increase in the strength of concrete (Figure 2). That is, in this case there is an increase in the rate of hydration reactions of cement minerals, which is fixed by increasing the strength of concrete over time. When a certain concentration is reached colloidal surfactant, the maximum strength of concrete is observed, which, depending on its composition in this case is $120-170 \%$ of the strength of concrete without additives.

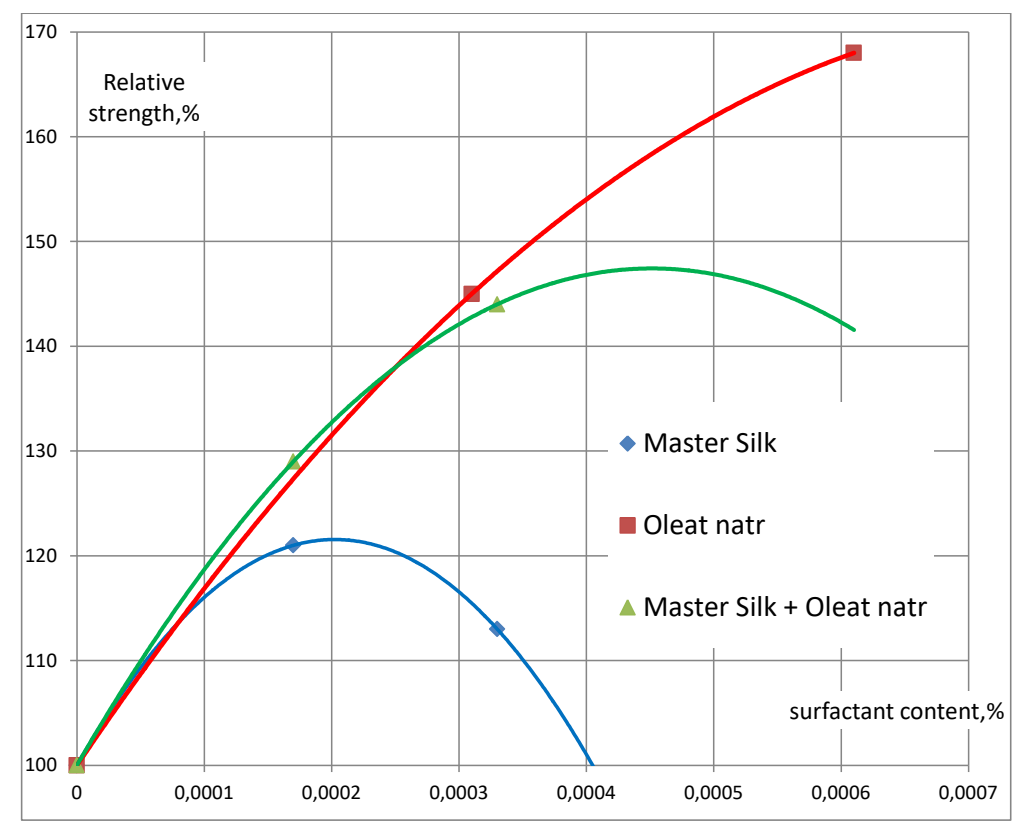

Figure 3. Relative strength of concrete (7 days)

A further increase in the amount of colloidal surfactant leads to a decrease in the rate of formation of concrete strength. This is due to the 
fact that the excess molecules of the colloidal surfactant begin to shield the cement particles, reducing the degree of their hydration.

The introduction of additional surfactant (in this case - Master Silk), reduces the concentration of colloidal surfactant when dimmers are formed and increases the strength of concrete at the age of 7 days (Figure 3), but there is no optimum content in the colloidal surfactant.

Obviously, this is due to the number of formed dimmers, which in this case are not only adsorbed on the surface of cement particles, but also dissolve these particles by molecules of molecular surfactant. At the age of $28 \mathrm{~d}$ and $\mathrm{b}$ there is a significantly reduced effect of colloidal surfactant on the strength of concrete (Figure 4), which once again confirms the catalytic nature of the process. X-ray phase analysis showed that the introduction of surfactants did not lead to changes in the neoplasms in concrete, which also confirms the catalytic nature of the nanocatalyst - dimmers of colloidal surfactant. That is, by this time the hydration reactions are almost complete, both in conventional cement and in cement to which a complex surfactant has been added.

The strength of concrete, which contains a mixture of surfactants meet is tough at art and you can achieve concrete without additives into a larger period of solidification (Figure 5). This issue requires further study, but does not negate the definite effect of the catalytic effect of nanoparticles dimmers of colloidal surfactants.

The results of complex studies have shown that the optimal concentration of sodium oleate in water for mixing is in the range of $10^{-4} \ldots 10^{-6} \mathrm{M}$. In the process of making a mixture of cement and water, carried out by mixing them, there is a destruction of fractal grids formed during the structuring of water. As a result, each part of the destroyed fractal grid will act as a structure-forming element, forming a new fractal grid around itself.

That is, to structure the largest volume of water, the source of hydrophobic hydration must be introduced into the water in a relatively high concentration, followed by gradual addition of water and stirring at a certain stage of dilution to obtain the desired degree of water structuring.

To confirm this position, solutions of sodium oleate in water of the same concentration $\left(10^{-6} \mathrm{M}\right)$ were prepared, but with a different number of degrees of reaching this concentration. The research results (Table 2) confirmed the hypothesis of the feasibility of achieving the desired concentration of the 
Alexandra Shyshkina

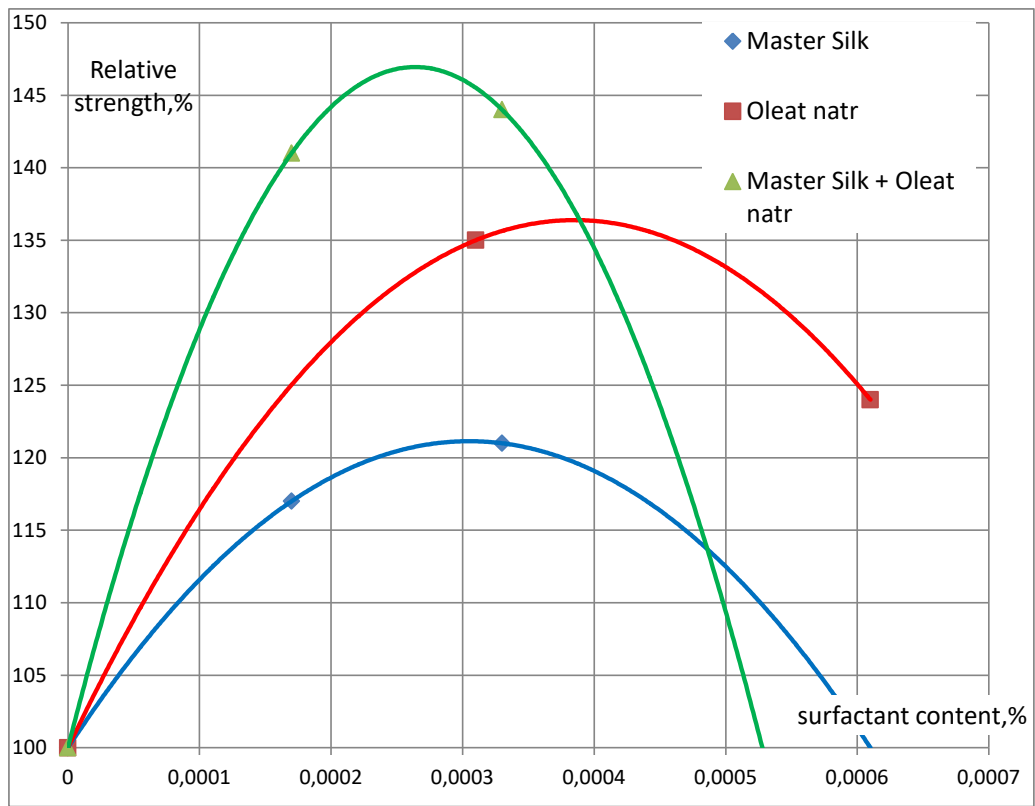

Figure 4. Relative strength of concrete (28 days)

source of hydrophobic hydration in the structuring of water, in particular molecules of hydrophobic colloidal surfactants.

Table 2

Relative strength of concrete depending on the number of degrees of water structuring

\begin{tabular}{|c|c|c|c|c|c|}
\hline \multirow{2}{*}{$\begin{array}{c}\text { Designation } \\
\text { of the } \\
\text { experiment }\end{array}$} & \multicolumn{5}{|c|}{$\begin{array}{c}\text { Relative strength of concrete, \%, } \\
\text { at the concentration of sodium oleate }\end{array}$} \\
\cline { 2 - 6 } & $\mathbf{0}$ & $\mathbf{1 0}^{-3} \mathbf{M}$ & $\mathbf{1 0}^{-4} \mathbf{M}$ & $\mathbf{1 0}^{-5} \mathbf{M}$ & $\mathbf{1 0}^{-6} \mathbf{M}$ \\
\hline U1 & 100 & - & - & - & - \\
\hline U2 & - & 112 & - & - & 130 \\
\hline U3 & - & 112 & 135 & - & 165 \\
\hline U4 & - & 113 & - & 149 & 168 \\
\hline U5 & - & 111 & 136 & 160 & 176 \\
\hline
\end{tabular}




\section{Chapter «Engineering sciences»}

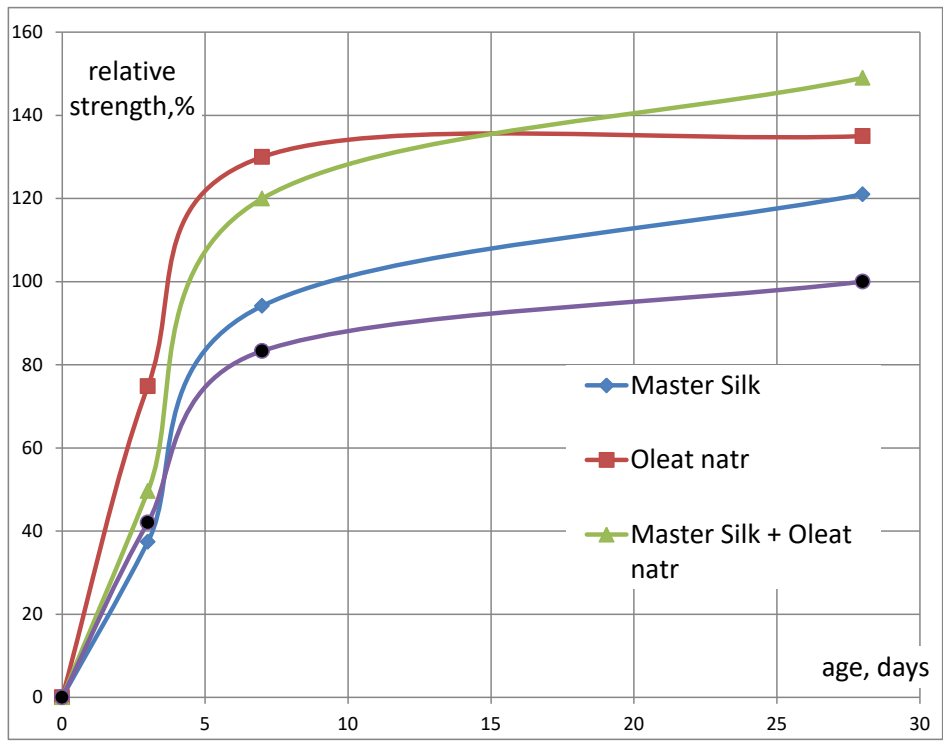

Figure 5. Relative strength of concrete

The results of studying the strength of concrete, which was prepared in water, which was structured with a sodium oleate solution by successive dilution, are shown in table 3 and table 4.

Table 3

The relative strength of concrete at the age of 7 days

\begin{tabular}{|c|c|c|c|c|c|c|c|c|c|}
\hline \multirow{2}{*}{ Modifier } & \multicolumn{6}{|c|}{ Relative strength of concrete, \%, at concentration modifier, $\mathbf{1 0}^{-\mathbf{5}} \mathbf{M}$} \\
\cline { 2 - 10 } & $\mathbf{0 , 8 6}$ & $\mathbf{1 , 4}$ & $\mathbf{1 , 7}$ & $\mathbf{2 , 8}$ & $\mathbf{3 , 4}$ & $\mathbf{4 , 2}$ & $\mathbf{2 7}$ & $\mathbf{8 7}$ & $\mathbf{5 9}$ \\
\hline sodium oleate & & 135 & & 168 & & 128 & & & \\
\hline
\end{tabular}

Notes: $100 \%$ strength is the strength of concrete on unstructured water

Table 4

The relative strength of concrete at the age of 28 days

\begin{tabular}{|c|c|c|c|c|c|c|c|c|c|}
\hline \multirow{2}{*}{ Modifier } & \multicolumn{8}{|c|}{ Relative strength of concrete, \%, at concentration modifier, $\mathbf{1 0}^{-\mathbf{5}} \mathbf{M}$} \\
\cline { 2 - 10 } & $\mathbf{1 , 1}$ & $\mathbf{1 , 4}$ & $\mathbf{2 , 8}$ & $\mathbf{3 , 4}$ & $\mathbf{4 , 2}$ & $\mathbf{5 , 5}$ & $\mathbf{2 7}$ & $\mathbf{8 7}$ & $\mathbf{5 9}$ \\
\hline sodium oleate & & 127 & 135 & & 124 & & & & \\
\hline
\end{tabular}

Notes: $100 \%$ strength is the strength of concrete on unstructured water 
Thus, it was found that the number of degrees of dissolution of sodium oleate in water to reach the desired concentration should be at least two (experiments U2-U5 table 2). Only then does the effect of structuring water with a hydrophobic colloidal surfactant have practical significance.

The use of sodium oleate solution (at the above concentrations, sequential dilution) to obtain concrete leads to an increase in the amount of bound water in the concrete, which indicates the acceleration and deepening of hydration of the mineral components of cement.

\section{Discussion}

The observed effect can only be explained by a change in the $\mathrm{pH}$ of water caused by the sorption of hydroxyl groups of water on the surface of the hydrocarbon portion of sodium oleate and also by considering the structure of water.

Bernal and Fowler formulated the first scientific hypothesis about the structure of water. Later it was confirmed in many respects, but much of it was clarified and revised.

During the second half of the 60 's and early 70 's of the $20^{\text {th }}$ century, there were variants of cluster models of water, in which in both microphases the molecules are connected by hydrogen bonds.

The clusters contain several hundred $\mathrm{H}_{2} \mathrm{O}$ molecules, which, like flickering clusters, continuously arise and break down due to local density fluctuations. Virtually all cluster hypotheses are based on the fact that liquid water consists of a network of quadrupled $\mathrm{H}_{2} \mathrm{O}$ molecules and monomers that fill the space between clusters. At the boundary surfaces of the clusters there are one-, two- or three-fold bound molecules. This model is also known as «shimmering clusters».

Currently, scientific research has shown that the physical properties of water and numerous short-lived hydrogen bonds between neighboring hydrogen and oxygen atoms in the water molecule create favorable opportunities for the formation of special structures - associates (clusters) that receive, store and transmit a variety of information. The structural unit of such water is a cluster consisting of clathrates, the nature of which is due to distant Coulomb forces.

Clathrates are specific compounds that are formed from molecules of water and molecules of another substance. The water molecules are 
enveloped (hydrated) by a monolayer of molecules of another substance without the formation of valence bonds. The substance seems to get inside the ball, the shell of which envelops it and consists of water molecules (Figure 6). Under natural conditions, cavities in water clathrates can be occupied by molecules of hydrocarbons (methane, argon, helium) and noble gases (argon), forming crystal hydrates.

Water, consisting of many clusters of different types, forms a hierarchical spatial liquid crystal structure that can perceive and store huge amounts of information (Figure 7).

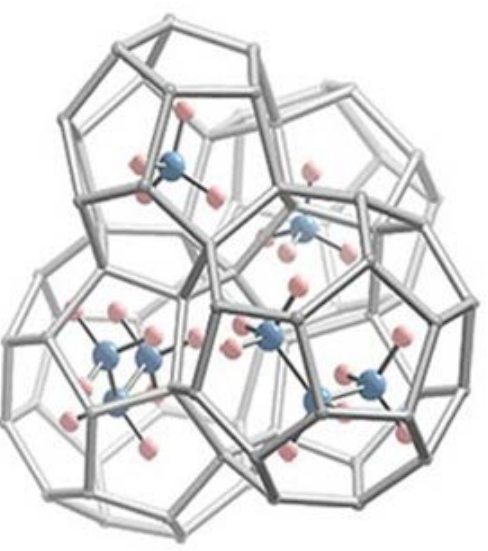

Figure 6. Is a diagram of clathrate

The well-known Russian researcher of water Stanislav Zenin and his associates in the period 1994-2003 built and proved a geometric model of the basic stable structural formation of water molecules (structured water).

According to Zenin, clusters and associates are the basis of the structural memory of water - long-term (stable associates) and short-term (labile, unstable associates). According to Zenin's hypothesis, water is a hierarchy of regular three-dimensional structures of «associates», which are based on a crystalline «quantum of water» consisting of 57 of its molecules, which interact with each other due to free hydrogen bonds.

Thus, stable clusters appear in the water, which carry very high energy and information of extremely high density. This structure is energetically advan-

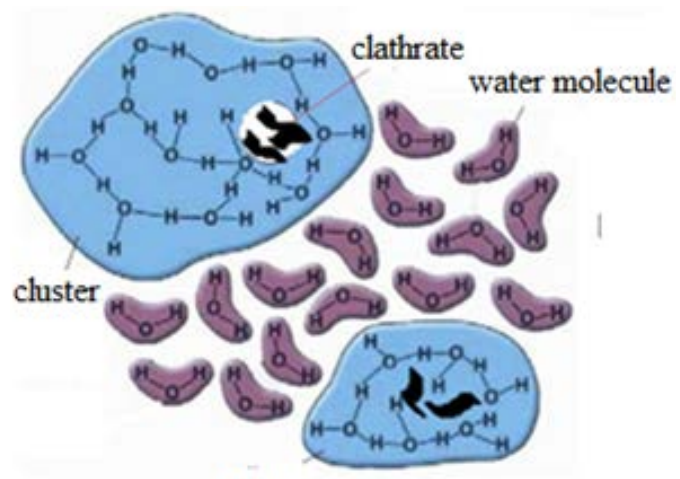
cluster

Figure 7. Clathrate-fractal model of water 
tageous and collapses with the release of free water molecules only at high concentrations of alcohols and similar solvents. «Water quanta» can interact with each other due to free hydrogen bonds, which leads to the emergence of higher-order structures consisting of 912 water molecules.

The influence of the ion on the thermal and translational motion of the nearest molecules can be divided into two components. The first component (hydrophilic hydration) is associated with the presence of positive or negative hydration; it increases with increasing temperature and decreases when going from solutions to ordinary water. The second component (hydrophobic hydration) is characterized by the fact that part of the solute has an inhibitory effect on the translational movement of molecules and is caused by the fact that part of the solution space corresponding to the proper volume of dissolved particles is inaccessible to a water molecule. This component grows with increasing solute particle size.

In the presence of inert solutes such as aliphatic hydrocarbons, the water undergoes hydrophobic hydration, resulting in a zone of floating icebergs. Frank and Evans attributed this unexpected phenomenon to the interaction of butter with whipped water, in which the weak polarizability of the inert solute results in an inability to transmit stimuli leading to the destruction of clusters. As a consequence, the impact on clusters is locally mitigated. In turn, the accumulations in the mitigation zone provide surface protection for the ice accumulations adjacent to them.

The fact that a variety of opposite chemical actions can lead to synergism in increasing ordering, which, in turn, can then increase under the action of a spatially ordered matrix, including, for example, cavities between regularly spaced crystallites of equal sizes, is consistent with the formation of longrange order and immobilization of water inside the membrane and at the interface between the membrane and the solution.

Large hydrophobic ions also cause ordering of the water structure. Having a more ordered structure than pure water, solutions of these salts require less work to dissolve the non-electrolyte, as a result of which the solubility of the latter increases. Polar groups are unable to interfere with hydrophobic hydration.

The stabilization of the structure of water occurs not so much due to the strengthening of hydrogen bonds near the dissolved particles (hydrophobic hydration), but due to an increase in the proportion of 
regions of the ordered structure, where water molecules are linked by strong tetrahedral hydrogen bonds.

The diameter of the hydrophobic hydration zone increases with an increase in the size of the non-polar part of the non-electrolyte molecule. Thus, hydrophobic hydration makes water dramatically stand out from all solvents. Hydrophobic hydration means the entire set of features of interactions with water of non-polar molecules and groups in an infinitely dilute solution.

The essence of hydrophobic hydration is based on the environment of molecules of non-polar or hydrophobic substances with a cell-like or clathrate hydration atmosphere.

In the optimal range of concentrations (in this case $10^{-4} \ldots 10^{-6} \mathrm{M}$ ) a fractal volume grid is formed, which occupies a significant volume in the aqueous system, and a local change in the concentration of hydroxyl groups near the molecules of sodium oleate leads to the capacitive effect of change $\mathrm{pH}$.

The obtained research results indicate the presence of a concentration interval of nanomodifiers - dimmers $\left(10^{-4} \ldots 10^{-6} \%\right)$, where the $\mathrm{pH}$ of the suspension decreases (Figure 8). The explained effect can be considered only in view of the change in the ionic production of water caused by the sorption on the surface of nanoparticles - dimmers of hydroxyl groups MPAR.

This acidification of the suspension is favourable for creating conditions for the formation of the structure of cement stone, because in this case there is a neutralization reaction between the most soluble form of calcium hydroxide cement and the formation of additional water molecules, which subsequently bind to less soluble hydration products of Portland cement.

At the same time, it is doubtful that under certain conditions nanoparticles - molecules of sodium oleate due to the effect of hydrophobic hydration form a continuous fractal network of water molecules.

At a certain interval of change of concentration of hydrophobic surfactant $\left(10^{-3} \ldots 10^{-6} \%\right)$ the specific electrical conductivity of the system practically does not change (Figure 9). This indicates a change in the ionic strength of the water caused by the sorption of hydroxyl groups on the surface of the dimmers introduced into the liquid.

Most likely, a fractal network of clathrates and accumulations of structured water is formed around the source of hydrophobic hydration (sodium oleate molecule), the size of which will depend on the degree of hydrophobic hydration of the system. 


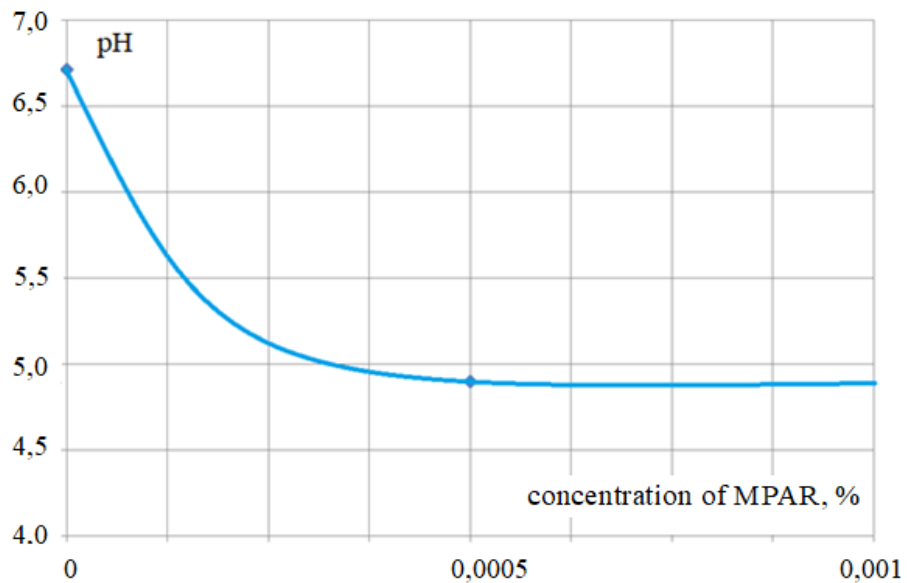

Figure 8. Changing the $\mathrm{pH}$ of the system depending on the concentration of hydrophobic surfactant

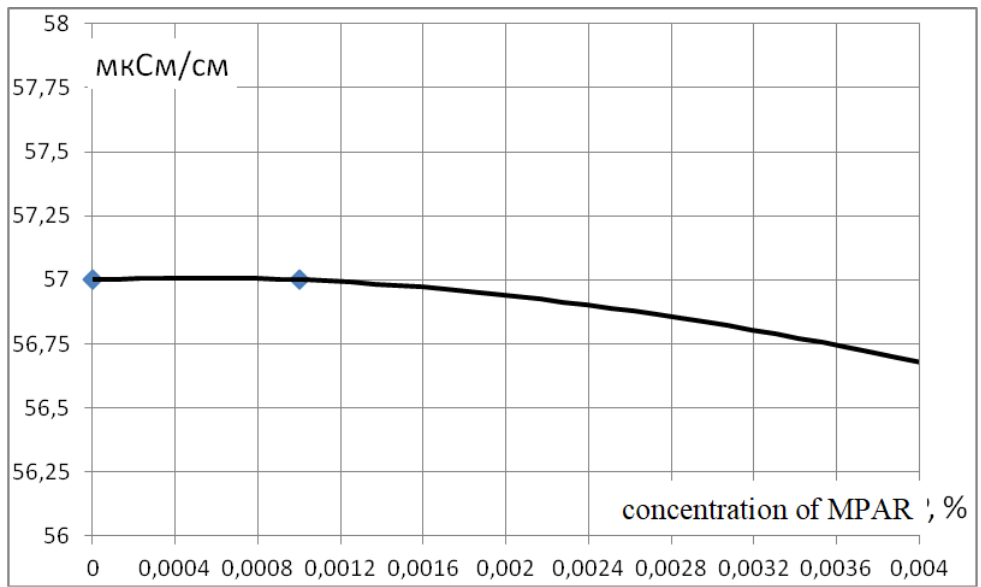

Figure 9. The dependence of the electrical conductivity on the concentration of hydrophobic surfactant 
To convert the entire volume of water into a fractal network requires a fairly high concentration of molecules-centers of hydrophobic hydration, but this can be done to some extent, the excess of which will lead to their aggregation (in particular, the formation of micelles from sodium oleate), which will limit the increase in fractal grids.

The introduction of hydrophobic surfactant molecules (MPAR) into water, which are in the form of dimmers, causes structuring of water (Figure 10).

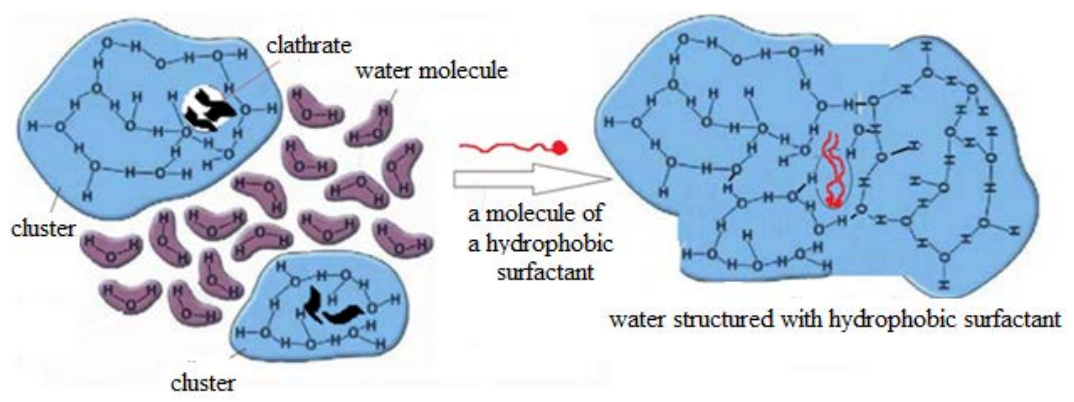

Figure 10. Structuring of water hydrophobic surfactant

That is, hydrophobic surfactant dimmers, which, depending on the type of MPAR, have sizes from 5 to $50 \mathrm{~nm}$ (ie, the size refers to nanoparticles) effectively carry out chemical activation of water, which explains the results of research.

\section{Conclusions}

The results of research obtained in the work allow us to conclude that surfactants in concrete should not solve the problems for which they are currently used.

That is, the use of colloidal hydrophobic aliphatic surfactants, as well as most hydrophilic surfactants, in extremely low concentrations will provide a significant increase in physical and mechanical properties of concrete without significantly reducing the water content, or without reducing the water content. This technological solution will reduce the chemical load on the concrete, provide sufficient plasticity of the concrete mixture and hardening time, simplify and reduce the cost of technology for the manufacture of concrete and reinforced concrete products. 
In addition, the results of the study lead to the following conclusions:

1. The increase of compressive strength of fine-grained concrete at introduction into water on the basis of which concrete is made, mixes of colloidal surfactants and molecular surfactants is proved. This process occurs due to processes that obey the laws of catalysis.

2. It is proved that the compressive strength of fine-grained concrete depends on the content of colloidal surfactants and molecular surfactants in the mixture. The optimal content of this mixture is from $0.00030 \%$ to $0.00070 \%$.

\section{References:}

1. Shishkin, O. O., Khilchenko O. P. (2007) Tekhnologiya betonu [Concrete technology]. Kriviy Rih: «Vidavnichiy dim». (in Ukrainian)

2. Khodakov, G. S. (1972) Tonkoe izmelchenie stroitelnykh materialov [Fine grinding of building materials]. Moscow: Stroyizdat. (in Russian)

3. Ratinov V. B., Rozenberg T. I. (1989) Dobavki v beton [Concrete admixtures]. Moscow: Stroyizdat. (in Russian)

4. Berezin I. V., Martinek K., Yatsimirskiy A. K. (1973) Fiziko-khimicheskie osnovy mitsellyarnogo kataliza [Physicochemical foundations of micellar catalysis]. Advances in chemistry, vol. 135, p. 10. (in Russian)

5. Mittel N. (1980) Mitselloobrazovanie, solyubilizatsiya i mikroemulsii [Micelle formation, solubilization and microemulsions]. Moscow: «Mir». (in Russian)

6. Shishkina O.O., Shishkin O.O. (2016) Doslidzhennya vplivu nanokatalizu na formuvannya mitsnosti reaktsiynogo poroshkovogo betonu [Investigation of the influence of nanocatalysis on the formation of the strength of reaction powder concrete]. Eastern-European Journal of Enterprise Technologies, vol. 1/6 (79), p. 55. (in Ukrainian)

7. Strizhak P. Ye. (2013) Nanorazmernye effekty v geterogennom katalize [Nanoscale effects in heterogeneous catalysis]. Theoretical and experimental chemistry, vol. 49.1, p. 1. (in Russian)

8. Shishkina A., Shishkin A. (2018) Research into effect of complex nanomodifiers on the strength of fine-grained concrete. Eastern-European Journal of Enterprise Technologies, vol. 2/6 (92), p. 29.

9. Shishkina A., Shishkin A. (2018) Study of the effect of micellar catalysis on the strength of alkaline reactive powder concrete. Eastern-European Journal of Enteprise Technologies, no. 3/6 (93), p. 46.

10. Shishkina A., Shishkin A. (2020) Application of the easy concentration effect in concrete technology. Innovative Technology in Architecture and Design (ITAD 2020). IOP Conf. Series: Materials Science and Engineering, 907. 012038. 